\title{
Forming Identity and Avoiding Hegemony in the Era of Globalisation
}

\author{
Vanessa Leonardi \\ Universita' di Ferrara
}

\begin{abstract}
The phenomenon of globalisation has further strengthened the relationship between cultural identity and language learning. The aim of this paper is to analyse the role of language in the formation of cultural identity and the role of culture in language teaching as an expression of identity that avoids hegemonic practices. Teaching languages inevitably necessitates teaching culture. Integrating culture into L2 teaching can help learners develop cultural awareness and cultural identity. In the first case, learners will become aware of the we versus they dichotomy created by false generalizations and stereotypes, and will be encouraged to develop tolerance and empathy towards different cultures. By comparing L1 and L2 similarities and differences learners will better understand, in terms of identity, their own place within the spectrum of cultures. Some scholars have heavily criticised ELT professionals and materials for their hegemonic tendencies. This paper, however, argues that teaching languages and culture naturally involves some sort of exclusionary practices which should not necessarily be viewed as hegemonic. The selection of a specific linguistic or cultural model, be it British or American English or other varieties, should not be viewed as an imposition of hegemony, but rather as a necessary means to achieve some kind of intelligibility.
\end{abstract}


92 Forming Identity and Avoiding Hegemony in the Era of Globalisation

\begin{abstract}
Keywords: globalization, cultural identity, language learning, L2 teaching, cultural awareness, stereotypes, hegemony, intelligibility
\end{abstract}

\title{
1. Introduction
}

Globalisation tends to be held responsible for a loss of identity all over the world since it has been accused of destroying differences among local communities, displacing people and imposing market homogenization. It seems that globalisation has greatly favoured strong economies and helped Western cultures to become predominant over 'weaker' cultures. This is true in the case of American economy and culture. Thus, globalisation is an unstoppable phenomenon that seems to homogenize and, at the same time, fragment peoples, economies, cultures and languages all over the world.

Bound to the concept of globalisation of economies and cultures is the notion of globalisation of languages that, in the last few years, has enormously favoured the English language. The global dominance of English plays a vital role in the relationship between cultural identity and globalisation.

These factors inevitably affect and challenge language teaching methodologies and practices in many different countries. In the teaching of the English language, in particular, the integration of cultural aspects along with the preference for a specific variety of English has been sometimes associated with a hegemonic practice aimed at spreading and further strengthening the role of English and its dominant status over other cultural and linguistic communities.

It is argued, however, that teaching foreign languages inevitably involves teaching culture, and at the same time, it involves some sort of exclusionary practices. In the case of English language teaching, in particular, the choice of adopting British English (BE) or American English (AE), among the most commonly used and taught varieties, 
should not be seen as an expression of hegemony or power imposition in a sort of 'colonization practice', but rather as a necessity to provide a model to refer to in order to achieve intelligibility and better assess learning.

\section{Language, Culture and Identity}

Language is undoubtedly a fascinating, challenging and controversial object of study. It allows communication since it is an external expression of internal thoughts and it is also an important marker of identity where group membership can differentiate people in terms of gender, age, social class, occupation, race and ethnicity based on the way these people talk and interact with one another in specific contexts. Language is an expression of a given cultural community, and it shares with it a mutual relationship whereby language is shaped by culture as culture is, in turn, shaped by language. The language of a given cultural community could not exist without its cultural beliefs and assumptions, norms and conventions, while culture could not exist without its language which allows it to be expressed in oral, written and even signed modes of communication. Language not only provides an important tool for communication, but also involves power, control and discrimination.

Throughout the years, some languages have become predominant over others and, as such, they have managed to establish themselves as lingua franca. Nowadays, English is the most commonly used language in the world. Its superior and global status is a result of complex historical, economic and political factors. English as the language of 'British colonialism' and 'American imperialism' has gained an independent status, and is no longer an exclusive property of English native speakers since it has been adopted by many linguistic communities all over the world. Is this possibly another form of colonization? If we reflect upon Crystal's (2003: 9) 
94 Forming Identity and Avoiding Hegemony in the Era of Globalisation

statement that "a language has traditionally become an international language for one chief reason: the power of its people," it can be assumed that teaching $\mathrm{BE}$ or $\mathrm{AE}$ could be a way of further strengthening this power over lower and weaker cultures, just like a new form of colonization. Eco (1995: 331) makes an interesting remark in this respect by claiming that "had Hitler won World War II and had the USA been reduced to a confederation of banana republics, we would probably today use German as a universal vehicular language, and Japanese electronics firms would advertise their products in Hong Kong airport duty-free shops in German.” Some people tend to view the global status of English as a tool for imposing Western values and cultures (mainly American) over others, and this belief has led several scholars to theorize about the linguistic imperialism of English, whose theories and approaches will be further analysed in paper.

Culture is a very complex and controversial issue to define since there are 'as many definitions of culture as there are fields of inquiry into human societies, groups, systems, behaviors and activities' (Hinkel 1999: 1). Broadly speaking, culture is "a set of ideas, beliefs, and ways of behaving of a particular organization or group of people” (Macmillan English Dictionary 2007: 359). Some people may adopt a belletristic approach to define culture as 'high' culture, that is, refinement, manners and intellectual properties; and it is desirable in most EFL courses in order to provide learners with the 'perfect model'. Others tend to perceive culture as 'popular' or 'mass' culture which, however, tends to be stigmatized because of its restrictive nature which limits cultural notions to purely tourist information or simplistic folklore (Steele \& Suozzo 1994). Culture can be acquired, taught, shared and manipulated through language. There seems to be, ipso facto, a close relationship between language and culture as 'a language is a part of culture, and a culture is a part of language; the two are intricately interwoven so that one cannot separate the two without losing the significance of either language or culture' (Brown 2000: 177). Byram (1989: 94) asserts that “the 
language holds the culture through the denotations and connotations of its semantics" whereas Kramsch (1998: 3) claims that language expresses, embodies and symbolizes cultural reality.

Having observed that language and culture are inextricably bound to each other, it is worth analysing how these issues impact on people's identity and, for the sake of this paper, on learners' identity in particular. Identity can be a very difficult and controversial term to define. Broadly speaking, it refers to the individual's perception of the self in relation to his or her group membership in a given cultural and linguistic community.

Several scholars have provided a series of challenging and influential theories with which to define 'identity' from a general perspective. DeVos (1992), for instance, claims that the phenomenon of identity formation is not a totally conscious process but rather it is influenced, to a certain extent, by some kind of unconscious psychological processes. Norton (1997: 410) claims that identity is a concept referring to 'how people understand their relationship to the world, how that relationship is constructed across time and space, and how people understand their possibilities for the future'. Bordieu (1977) in his study of identity, deals with the relationship between identity and symbolic power. He maintains speech acquires meaning through the speakers themselves who, in turn, are understood by others sharing with them specific social relationships, most of which are unequally structured and thus display, to a greater or lesser degree, a sort of power relation between speakers and hearers. Weedon (1987: 32) works within a feminist poststructuralist perspective and focuses on power relations through the notion of 'subjectivity' defined as 'the conscious and unconscious thoughts and emotions of the individual, her sense of herself and her ways of understanding her relation to the world'. In her opinion, the individual and the social world are bound to one another through language, and following Foucault she claims that "subjectivity is produced in a whole range of discursive practices -- economic, social, political -- the meanings 
96 Forming Identity and Avoiding Hegemony in the Era of Globalisation

of which are a constant site of struggle over power" (21). West (1992) relates the notion of identity to desire which is, in turn, bound to the distribution of material resources in a given sociocultural community. Access to these material resources implies acquisition of power and security, and above all recognition and stability.

Other scholars, however, have discussed the issue of identity in relation to language acquisition. McKay and Wong (1996) claim that language learners display several different identities according to the kind of power relations and discourse practices they are exposed to in class in a sort of social negotiation process. NortonPeirce (1995) draws her theory from the poststructuralist definition of social identity as a multi-layered construct based on the notion of investment rather than motivation. Learners, indeed, invest their time and efforts to learn a language with the expectation of receiving a 'wider range of symbolic and material resources, which will in turn increase the value of their cultural capital' (17).

Therefore, language is bound to culture, and they both influence learner's identity, since language use creates or produces discourse which is a reflection of one's group membership. This group membership is also referred to as 'cultural identity', which is shaped by a variety of factors, which according to Sysoyev (37), includes socio-economic racial/ethnic, geopolicical, religious, gender forces as well as language.

In order to teach culture in a foreign language class, it is vital to make a comparison between L1 and L2 cultural differences and similarities without ascribing value to one or the other culture. This can help learners to see and understand differences in a positive way without judging the quality of a specific culture but by attempting to recognise how these differences can help them improve the quality of their language use.

From a European perspective, it is becoming more common to refer to a European identity, and the motto 'unity in diversity' seems 
to reiterate the concept of multiple identities co-existing in a peaceful and tolerant environment. Differences should be welcomed and appreciated, and awareness of diversity may help multiple identities merge into one. The same reasoning applies to the idea of a global identity, where different cultural communities merge into a single identity through the medium of a common language.

There is a widespread belief that fluency and accuracy in language learning are successful elements in foreign language learning. However, a language cannot be merely reduced to a set of grammatical rules and a rich list of vocabulary. A language is an expression of identity embedded in a given culture, and its successful communication requires more than just linguistic knowledge. Thomas (1983) perceives linguistic competence as a combination of 1) grammatical competence, or 'abstract' knowledge of phonology, syntax, semantics and so forth and 2) pragmatic competence, viewed as the ability to use language successfully within a given context. This is why the teaching of culture is vital in terms of successful communication, and as Dash (2004: 12) asserts, "Openness to different pragmatic interpretations consistent to sensitivities of various cultures and social groups would be something to keep in mind as well as an approach free of stereotypical judgements.”

\section{Culture in L2 Teaching}

L2 teaching cannot be fully comprehensive in its approach unless it includes culture. Most of the time, L2 learners who lack cultural competence find it hard to use language correctly in appropriate situations. In this respect, Bada (2000: 101) claims that "the need for cultural literacy in ELT arises mainly from the fact that most language learners, not exposed to cultural elements of the society in question, seem to encounter significant hardship in communicating meaning to native speakers.” 
98 Forming Identity and Avoiding Hegemony in the Era of Globalisation

It is interesting that there does not seem to be a common agreement among ELT professionals on whether culture should be included in language teaching courses, but research in applied linguistics proves that culture exerts a great deal of influence over L2 teaching both linguistically (affecting semantic, pragmatic and discourse levels of language teaching and language use) and pedagogically (affecting both the choice of materials to be used and the teaching methods employed) (McKay 2003). Furthermore, perception is another influential factor in the teaching of culture. Positive perception of the target culture (TC) enhances L2 learning, whereas a negative perception of the TC or a sense of competition between the source culture (SC) and the TC may seriously hinder L2 learning (Schumann 1976; Brown 2000).

Within the field of ELT/ESL several scholars have dealt with the issue of how pedagogy promotes Western values in a sort of cultural imperialism as a direct result of linguistic imperialism. Phillipson (1992), Auerbach (1993), Canagarajah (1999) and Skutnabb-Kangas (2000) are among the most influential scholars who have heavily criticised both ELT professionals and materials for their hegemonic practices and ideologies clearly evident in the way they deal with the target culture. Nevertheless, it is worth noting that teaching English inevitably involves the adoption of one model or variety (mainly BE or AE), which inevitably excludes other varieties. This choice, however, cannot always be regarded with suspicion, and cannot always be defined as a clearly hegemonic practice aimed at colonizing the classroom. There may be, indeed, many reasons lying behind this choice, such as:

1) The teacher's nationality and thus mother tongue (both in the case of native speakers of English as well as bilingual speakers);

2) The teacher's linguistic and cultural knowledge of a particular variety (of English); 
3) The type of language certificate that is sought (ESOL Cambridge, such as PET or FCE or TOEFL);

4) Availability and ease of retrieval of material in a specific country;

5) Lack of time or expertise with which to cover a wider range of linguistic and cultural elements derived from different varieties of English.

Smith (1976) claims that in an increasingly globalised world there is no need to refer to or stick to a specific language and culture variety, because English is nowadays an international language, and as such is de-nationalised. Its main purpose is to allow people from different linguistic and cultural backgrounds to communicate through the medium of English. This is true in the case of culture teaching that cannot be confined to a single target culture model, be it British, American, Australian, or so forth. Culture needs to be understood from an intercultural perspective where a variety of people coming from different parts of the world come into contact. These people include L1 speakers, L2 speakers and EFL speakers in accordance with Graddol's (1997) classification of users of English around the world.

The teaching of culture should be ultimately aimed at promoting and increasing sensitivity to cultural difference. Several scholars have developed different models in this respect; for example Bennet (1993) created a Developmental Model of Intercultural Sensitivity (DMIS), employing concepts from cognitive psychology and constructivism, which is divided into two major stages: 1) ethnocentric stages (of denial, defence, and minimization) and 2) ethno-relative stages (of acceptance, adaptation, and integration). The notion of 'ethnocentrism' refers to an individual's own culture that is experienced as central to reality, whereas 'ethno-relativism' means an individual's culture that is experienced in the context of other cultures. A similar approach is proposed by Salyer (1993) with 
100 Forming Identity and Avoiding Hegemony in the Era of Globalisation

a six-stage model of cross-cultural appreciation, including 1) ignorance, 2) rejection, 3) approximation, 4) awareness, 5) approval and 6) versatility.

The teaching of culture can help avoid stereotypes and prejudices (Nemni 1992). It should set clear goals, in line with Tomalin and Stempleski (1993: 7-8), who in order to help students, modified Seelye's (1988) previous goals of cultural instruction:

1. To develop an understanding of the fact that all people exhibit culturally-conditioned behaviour;

2. To develop an understanding that social variables such as age, sex, social class, and place of residence influence the ways in which people speak and behave;

3. To become more aware of conventional behaviour in common situations in the target culture.

4. To increase their awareness of the cultural connotations of words and phrases in the target language;

5. To develop the ability to evaluate and refine generalizations about the target culture, in terms of supporting evidence;

6. To develop the necessary skills to locate and organize information about the target culture; and

7. To stimulate intellectual curiosity about the target culture, and to encourage empathy towards its people.

It can therefore be hypothesized that the problem does not lie in the choice of including or excluding the teaching of culture because this seems to be a necessary condition for the successful teaching of a foreign language, but rather in the way culture is presented and transmitted to learners. Any such practice should in principle be entirely hegemony-free. 


\section{Linguistic Imperialism and Hegemonic Attack in a Postcolonial Era?}

Before analysing the concept of linguistic imperialism and its impact upon teaching practices, it is fundamental to understand what is meant by 'imperialism'. Imperialism tends to be defined in negative terms due to its strict association with the issue of power. The Macmillan English Dictionary (2007: 756) provides the following definition: "The actions of a powerful country that tries to gain control or influence over the economic, political, and social life of weaker countries." Imperialism takes on several forms as also acknowledged by Galtung (1980: 128) and more precisely economic, political, military, communicative, cultural and social forms. Objections, however, can be raised to his theory in that he makes a distinction between 'centre' and 'periphery' and suggests that imperialism consists of a "relationship whereby one society can dominate another" (107) without explicitly clarifying who is dominating who. In the era of globalisation, it is clear that the concept of imperialism refers to the USA and it seems probable, in this respect, that this over-reaction to the phenomenon of globalisation is due to the association of American imperialism with a sort of new wave of colonization in all fields of society.

As far as the teaching field is concerned, it seems that in the last few years there has been a shift in the way the English language and culture are taught in class and presented through materials and textbooks. This shift moved the focus of attention from the British and American varieties to a more 'global' or 'international' English, in an attempt to provide learners with a more 'global' and less 'imperialistic' variety of English. Although some people claim that choosing to teach $\mathrm{BE}$ or $\mathrm{AE}$ means teaching an 'imperialist language in a postcolonial era', this claim is not totally supported by evidence but it is rather based upon misconceptions and confusion. Most of these attacks are nowadays motivated by hostility towards the 
102 Forming Identity and Avoiding Hegemony in the Era of Globalisation

phenomenon of globalisation, where it is the USA rather than the UK that plays a fundamental role.

The expression 'linguistic imperialism' refers to a sort of colonization practice whereby a linguistic community imposes its control over others. Linguistic imperialism has been defined and approached in many different ways throughout the years, and at times it has even been labelled as ‘linguistic racism'. Ansre (1979: 12-13) provided a general definition of linguistic imperialism viewed as a sort of mindcontrol practice associated with attitudes and ideology:

The phenomenon in which the minds and lives of the speakers of a language dominated by another language to the point where they believe that they can and should use only that foreign language when it comes to transactions dealing with the more advanced aspects of life such as education, philosophy, literature, governments, the administration of justice, etc. [...] Linguistic imperialism has a subtle way of warping the minds, attitudes, and aspirations of even the most noble in a society and of preventing him from appreciating and realizing the full potentialities of the indigenous languages.

Phillipson (1992: 47) perceives the linguistic imperialism of English as 'the dominance of English [...] asserted and maintained by the establishment and continuous reconstitution of structural and cultural inequalities between English and other languages'. This statement clearly implies a distinction between structural inequalities referring to material properties, and cultural inequalities referring to immaterial or ideological properties. It also implies that English exerts a powerful influence over other languages in a sort of relationship between dominating vs dominated languages. In his opinion, linguistic imperialism is a sub-type of linguicism defined as 'ideologies, structures, and practices which are used to legitimate, 
effectuate, and reproduce an unequal division of power and resources [...] between groups which are defined on the basis of language' (47). He claims that this is a sort of umbrella term which includes two important ELT practices, such as Anglocentricity and Professionalism. The former refers to the English language domination over other weaker and dominated languages and cultures which are consequently devaluated (1992: 48). The latter refers to ELT pedagogy where 'professional discourse around ELT disconnects culture from structure' thus reducing language teaching to a mere set of technical skills and issues and excluding, at the same time, all the socio-cultural, economic and political matters in this respect. His attack (1992: 185) to the ELT field is based on five main tenets or fallacies:

\subsection{The Monolingual Fallacy}

This refers to the widespread belief that success of foreign language teaching and learning depends on the exclusive use of English as the only communication medium and no other languages are allowed in the classroom. This ban of using other languages clearly reflects a commonly voiced belief that the use of the mother tongue in FL classes hinders successful learning. Many theorists, such as Phillipson himself, have also viewed this practice as a way to denigrate the role of other languages in a sort of English colonization. On the contrary, the use of L1 can prove to be a useful tool to compare similarities and differences and, furthermore, it is a more natural way to deal with learning.

\subsection{The Native Speaker Fallacy}

The privileged status of the native speaker in ELT is a very common issue in FL teaching. Widdowson (1994) asserts that the reason for employing native speakers is bound to the notion of 
104 Forming Identity and Avoiding Hegemony in the Era of Globalisation

'authenticity' that can only be taught by natives. However, in the context of learning, non-native speakers may be more suitable and prepared because they know exactly what is appropriate in language learning situations. Although some people hold the opinion that native teachers are better qualified than non-native speakers in producing fluid, accurate and idiomatically correct language, it is also true that in most English-speaking countries, people are not taught their own phonological and grammatical system, whereas at least in many European countries, this is the norm for both L1 and L2 learning. In addition, the successful teacher of foreign languages should be well informed about the learners' language systems (both phonological and grammatical systems) and cultural background. Thus, there seems to be more evidence that non-native teachers are better qualified teachers compared to natives.

\subsection{The Early Start Fallacy}

Within the field of applied linguistics, there seems to be a widespread belief that the earlier a person is taught a language (presumably when he or she is a child) the better the result. It is therefore claimed that lowering the starting age is a vital factor for successful language learning. Nevertheless, age should not be isolated from other variables that to a greater or lesser degree affect learning, such as linguistic, cognitive, social, affective and pedagogical factors. In India, for instance, where English is taught since primary school, the results are disappointing and thus the claim about 'the early start' acquisition of a foreign language cannot be supported.

\subsection{The Maximum Exposure Fallacy}

According to this tenet, the more English is taught, the better the results. The same objections covered in the section above (point 3) can be applied to this fallacy in that exposure is only one variable to 
be taken into account along with a series of others. Furthermore, this tenet contrasts with a series of theories in language acquisition, such as Krashen's (1985) input hypothesis which states that comprehendsible input, or quality of the input, is more important than the quantity of the input. Furthermore, this tenet does not take into consideration issues such as the learners' overall cognitive- academic proficiency in their mother tongue, which, if it is well-developed, may indeed facilitate L2 learning (Phillipson 1992: 212).

\subsection{The Subtractive Fallacy}

According to this tenet, the standards of English may drop if other languages are used in the classroom. Phillipson perceives this tenet, along with the previous ones, as yet another way to impose and maintain the privileged status of English over other linguistic and cultural communities. The continued use of English is a way to ensure that its role as 'colonial' language will not diminish. This creates a problem, however, in terms of being able to meet the high demand for English teachers. The higher the demand, the more difficult to find an adequate number of qualified teachers. This means that in some countries, in order to meet the demand for English, under-qualified teachers will be employed. In other words, it is the increasing demand for English itself that is responsible for the decrease of its standards.

\section{Counter-hegemonic Solution(s)}

Although some theorists, such as Naysmith (1987), Phillpson (1992) and Pennycook (1995), among the most influential claim that English, far from being neutral, is indeed "the language of international capitalism” (Naysmith 1987: 3), it is also worth noting that not all theorists working within the field of Applied Linguistics 
106 Forming Identity and Avoiding Hegemony in the Era of Globalisation

share this view. Significant signs of resistance to this 'imperialistic hegemony' began to emerge through the development of other theories based on so-called 'linguistic hybridity'. The notion of hybridity challenges the hegemony of English and allows retention of cultural identity. Furthermore, a series of proposals have been suggested by several scholars in order to avoid or resist hegemonic practices.

Rajagopalan (1999) claims that violence in languages is a direct consequence of power inequalities embedded in human relations. It is not English itself that is responsible for the loss of local and regional languages; rather this is mainly due to political factors that cannot be controlled by linguists and language teachers. Rajagopalan also believes that English, mainly through technology and mass media influence, makes an invaluable contribution to the global spread of multiculturalism. However, Canagarajah (1999) rejects Rajagopalan's hybridity-based view and believes that the only way to fight against the hegemony of this 'global' English is to reintroduce the use of the mother tongue(s) into the foreign language teaching classes.

Booij (2001) proposes to use English globally, without any cultural reference to a specific variety, by adopting an international lexicon and neutralizing lexical differences among English varieties. This could be accomplished by creating a global English dictionary, and giving up the British Received Pronunciation (RP) model. Furthermore, he suggests following Quirk's Nuclear English model which calls for a simplification in morphology and syntax. Finally, he concludes that "stylistically, international English will thus be less rich than the national varieties, but it will suffice as a means of international communication, in particular if it will also have a restricted lexicon, and allows for the coining of new, semantically transparent complex words" (355).

Another solution could be to adopt Freire's (1970) approach to language teaching as expressed in Pedagogy of the Oppressed in order to turn an oppressive and dominant learning environment into 
a more neutral field through two major stages: "In the first, the oppressed unveil the world of oppression and through the praxis commit themselves to its transformation. In the second stage, in which the reality of oppression has already been transformed, this pedagogy ceases to belong to the oppressed and becomes a pedagogy of all people in the process of permanent liberation" (54). If this methodology or pedagogy is applied to any English language teaching course, then it could be a valid solution to counterattack any hegemonic ideology attached mainly to British and American English varieties. This could be accomplished by asking learners how they perceive the English language and its use in their country as well as all over the world. If they see it as an international language adopted and adapted by several different communities around the world, this means that they do not feel subjected to or dominated by it. Nevertheless, in order to succeed in this task, more emphasis should be laid upon teacher training programmes aimed at raising awareness of the social, political and economic implications of teaching and using English for international communication. Teachers should promote a new vision of English as an international language rather than a foreign language belonging to any one linguistic and cultural community that adopts it. This will, in turn, help strengthen their identity as legitimate speakers of English where different cultures are addressed, analysed and compared from a positive international perspective that is all-inclusive.

The key factor is to think of English in a global sense and to consider ways in which it is perceived locally. This is also acknowledged by McKay (2002: 129), who asserts that:

The concept of thinking globally but acting locally is highly relevant to the teaching of EIL. The evidence clearly suggests that the use of EIL will continue to grow, an international language that belongs, not just to native speakers, but to all 
108 Forming Identity and Avoiding Hegemony in the Era of Globalisation

of its users. Given this shift in ownership, the time has come for decisions regarding teaching goals and approaches to be given to local educators so that they can take their rightful place as valid users of English. For, in the end, they are in the best position to understand what their students need to know, and to encourage them to learn and use English fully to participate in our growing global community.

The ideal solution is to have counter-hegemonic bilingual or multilingual classes where a variety of cultures are represented, not in a competitive way, but rather in a comparative way to better understand and appreciate 'diversity'. In terms of material to use, it is fundamental that this be written in English but reporting on the learners' own cultural background as well as cultural elements, places and events from different linguistic communities. Teachers should therefore tailor materials and teaching methodologies and approaches to learners' needs analysis.

\section{Conclusion}

Although the topic of teaching culture in foreign language classes is nothing new, its application in language courses helps learners function properly and effectively in another language and in another cultural community. Culture must be fully integrated as a vital component of language learning to teach students how to be successful in their communication in a foreign language. The teaching of culture does not merely consist in teaching greetings, forms of address, how to make requests etc., but should teach both awareness and sensitivity. This implies strategies and techniques to adapt the use of English to learn, understand and appreciate diversity as an enrichment factor as well as a positive value. Language pedagogy should "prepare learners to be both global and 
local speakers of English and to feel at home in both international and national cultures” (Kramsch \& Sullivan 1996: 211).

The problem is that some scholars and ELT professionals regard the use of a particular variety as a sort of colonization practice aimed at further strengthening the superior role of English and reinforcing the Anglo-American political and economic power. Paradoxically, if ELT books and teaching materials from the West are used differently from the way they were originally conceived and planned by their author, this act can be regarded as both a deliberate expression of appropriation and of resistance. Language and culture teaching inevitably involves a series of selections and exclusions as well as some forms of appropriation, but one cannot always regard these choices and practices as either 1) an expression of colonialism (or linguistic imperialism) or 2) resistance to foreign influences. These choices and practices are, most of the time, simply aimed at achieving intelligibility, and no offense or mind-controlling process is deliberately involved. Teaching English may to a certain extent involve one or other of these two forms of ideology, colonialism or appropriation, but they do not necessarily imply negative connotations of power, control and fight.

English language teaching is a vital component in the identitybuilding process. There can be a negative identity-building process, in which national identity is contrasted with other people's national identity in a sort of in-group (superior) versus out-group (inferior) perspective, and a positive identity-building process, where cultures are compared without ascribing too much value to one or another, but in a way which highlights similarities and differences between them so as to enrich learners' cultural knowledge.

There is a real necessity for language teachers to use more multicultural materials to present and represent different communities (not necessarily native-speaking countries), in order to avoid hegemonic practices bound to the use of $\mathrm{BE}$ or $\mathrm{AE}$ in class. At the same time they also need to meet language needs in a global 
110 Forming Identity and Avoiding Hegemony in the Era of Globalisation

community characterised by a multiplicity of discourses, cultures and identities.

Finally, it is felt that before deciding whether to include culture in English language teaching and selecting appropriate materials, all teachers should carefully reflect upon the following factors: 1) the role of English as international language, and 2) the role of culture in English language teaching.

\section{References}

Ansre, G. 1979. Four Rationalisations for Maintaining European Languages in Education in Africa. African Languages 5.2, $10-7$. Auerbach, E. R. 1993. Reexamining English Only in the ESL Classroom. TESOL Quarterly 27, 9-30.

Bada, E. 2000. Culture in ELT. Cukurova University Journal of Social Science 6, 100-10.

Bennet, M. 1993. Towards Ethnorelativism: a Developmental Model of Intercultural Sensitivity. In R. M. Paige (ed.) Education for the Intercultural Experience, Yarmouth, ME: Intercultural Press.

Booij, G. 2001. English as the Lingua Franca of Europe: a Dutch Perspective. Lingua e Stile 36.2, 347-58.

Bordieu, P. 1977. The Economics of Linguistic Exchanges. Social Science Information 16, 645-68.

Brown, H. D. 2000. Principles of Language Learning and Teaching, White Plains, NY: Addison Wesley Longman.

Byram, M. 1989. Cultural Studies in Foreign Language Education, Clevedon: Multilingual Matters Ltd.

Canagarajah, A. 1999. On EFL Teachers, Awareness, and Agency. ELT Journal 53, 207-14.

Crystal, D. 2003. English as a Global Language, Cambridge: Cambridge University Press.

Dash, P. 2004. Cross-cultural Pragmatic Failure: A Definitional 
Analysis with Implications for Classroom Teaching. Asian EFL Journal 6.3, 1-17.

DeVos, G. 1992. Social Cohesion and Alienation: Minorities in the United States and Japan, San Francisco, CA: Westview Press.

Eco, U. 1995. The Search for the Perfect Language, Oxford: Blackwell. Freire, P. 1970. Pedagogy of the Oppressed, $4^{\text {th }}$ edition, London: The Continuum International Publishing Group.

Galtung, J. 1980. The True Worlds: A Transnational Perspective, New York: Free Press.

Graddol, D. 1997. The Future of English? London: The British Council.

Hinkel, E. 1999. (ed) Culture in Second Language Teaching and Learning, Cambridge: Cambridge University Press.

Kramsch, C. \& P. Sullivan. 1996. Appropriate Pedagogy. ELT Journal 50.3, 199-212.

Kramsch, Claire. 1998. Language and Culture, Oxford: Oxford University Press.

Krashen, S. 1985. The Input Hypothesis: Issues and Implications, London: Longman.

McKay, S \& S. Wong. 1996. Multiple Discourses, Multiple Identities:

Investment and Agency in Second-language Learning Among Chinese Adolescent Immigrant Students. Harvard Educational Review 66. 3, 577-608.

McKay, S. 2002 Teaching English as an International Language: Rethinking Goals and Approaches, Oxford: Oxford University Press.

McKay, S. 2003. The Cultural Basis of Teaching English as an International Language. TESOL Matters, 13.4, 1-4.

MacMillan English Dictionary for Advanced Learners. 2007. $2^{\text {nd }}$ edition, London: MacMillan.

Naysmith, J. 1987. English as Imperialism? Language Issues 1.2, 3-5. Nemni, M. 1992. Mefiez-vous du Discours Interculturel!. Canadian Modern Language Review 49.1, 10-36. 
112 Forming Identity and Avoiding Hegemony in the Era of Globalisation

Norton, B. 1997. Language, Identity and the Ownership of English. TESOL Quarterly 31.3, 409-429.

Norton-Peirce, B. 1995. Social Identity, Investment, and Language

Learning. TESOL Quarterly 29.1, 9-31.

Pennycook, A. 1995. English in the World / The World in English, in J. W. Tollefson (ed), Power and Inequality in Language Education, 34-58. Cambridge: Cambridge University Press.

Phillipson, R. 1992. Linguistic Imperialism, Oxford: Oxford University Press.

Rajagopalan, K. 1999. Of EFL Teachers, Conscience, and Cowardice. ELT Journal 53, 200-06.

Salyer, M. 1993. Educators and Cultural Diversity: A Six-stage Model of Cultural Versatility. Education 113.3, 503-508.

Schumann, J. 1976. Social Distance as a Factor in Second Language Acquisition. Language Learning 26, 135-143.

Seelye, H. 1993. Teaching Culture, Lincolnwood, IL: National Textbook Company.

Skutnabb-Kangas, T. 2000. Linguistic Genocide in Education - or Worldwide Diversity and Human Rights, Mahwah, New Jersey: Lawrence Erlbaum.

Smith, L. (1976) English as an International Auxiliary Language. RELC Journal 7.2, 38-43.

Steele, R. \& A. Suozzo. 1994. Teaching French Culture: Theory and Practice, Linolnwood, IL: National Textbook Company.

Sysoyev, P. V. 2001. Individual's Cultural Identity in the Context of Dialogue of Cultures. Tambov, Russia: The Tambov State University Press.

Thomas, J. 1983. Cross-cultural Pragmatic Failure. Applied Linguistics 4, 91-112.

Tomalin B. and S. Stempleski. 1993. Cultural Awareness, Oxford: Oxford University Press.

Weedon, C. 1987. Feminist Practice and Poststructuralist Theory. London: Blackwell. 
West, C. 1992. Identity: A Matter of Life and Death. October 61, 1992, 20-23.

Widdowson, H. 1994. The Ownership of English. TESOL Quarterly 28.2, 377-89.

Vanessa Leonardi

Faculty of Economics, Universita' di Ferrara

Via Voltapaletto 11-44100 Ferrara, Italy

Phone: +39 0532 293420; Email: vanessa.leonardi@unife.it

Received in Nov, 2009; Reviewed: Nov, 2009; Revised version received in Nov, 2009 